$07 ; 15$

\title{
Новый тип газовых сенсоров на основе термовольтаического эффекта в оксиде цинка, неоднородно легированном примесями переменной валентности
}

\author{
(c) И.А. Пронин ${ }^{1,2}$, Н.Д. Якушова ${ }^{1}$, Д.Ц. Димитров ${ }^{3}$, \\ Л.К. Крастева ${ }^{3}$, К.И. Папазова ${ }^{3}$, А.А. Карманов ${ }^{1}$, \\ И.А. Аверин ${ }^{1}$, А.Ц. Георгиева ${ }^{4}$ В.А. Мошников ${ }^{1,2}$, \\ Е.И. Теруков ${ }^{5}$
}

${ }^{1}$ Пензенский государственный университет, Пенза, Россия

${ }^{2}$ Санкт-Петербургский государственный электротехнический университет „ЛЭТИ“, Санкт-Петербург, Россия

${ }^{3}$ Софийский университет „Св. Климент Охридский“, София, Болгария

${ }^{4}$ Университет Флориды, Гейнсвилл, США

${ }_{5}^{5}$ Физико-технический институт им. А.Ф. Иоффе РАН, Санкт-Петербург,

Россия

E-mail: pronin_i90@mail.ru

Поступило в Редакцию 20 февраля 2017 г.

Предложен новый тип потенциометрических газовых сенсоров на основе термовольтаического эффекта, возникающего в сандвич-структурах $\mathrm{ZnO} / \mathrm{ZnO}-\mathrm{Fe}$, полученных золь-гель-методом, при их равномерном нагреве без градиента температур. Установлено, что существенный вклад в значения газочувствительности вносит толщина верхнего легированного слоя.

DOI: 10.21883/PJTF.2017.18.45028.16754

В настоящее время необходимость разработки дешевых индикаторов токсичных и горючих газов стимулирует разработку новых типов газовых сенсоров, позволяющих увеличить значения газочувствительности и селективность, уменьшить габаритные размеры и энергопотребление. Для анализа газовых сред изготавливается и используется большое количество типов сенсоров: кондуктометрические, амперометрические, потенциометрические, кулонометрические и др. [1-3].

В настоящей работе авторами предложен новый тип потенциометрических газовых сенсоров на основе термовольтаического эффекта 
в оксиде цинка. Указанный эффект, по всей видимости, относится к семейству родственных эффектов спонтанной генерации электрического напряжения, обнаруженных на данный момент в небольшом числе материалов (FeS [4], $\mathrm{SmS} \mathrm{[5],} \operatorname{Pr}_{0.6} \mathrm{Ca}_{0.4} \mathrm{MnO}_{3}$ [6], $\mathrm{Si}_{1-x} \mathrm{Ge}_{x}$ [7], $n-\mathrm{Si} / p-\mathrm{Si}_{1-x} \mathrm{Ge}_{x}[8]$ и др.). Несмотря на то что были предложены различные механизмы возникновения спонтанного электрического напряжения в этих материалах, его физические принципы до сих пор недостаточно изучены.

Авторами данной работы впервые был обнаружен термовольтаический эффект в образцах оксида цинка, представляющих собой сандвичструктуры $\mathrm{ZnO} / \mathrm{ZnO}-M(M=\mathrm{Cu}, \mathrm{Fe})$, при их равномерном нагреве без градиента температур [9]. Для объяснения природы отмеченного эффекта были предложены модельные представления, базирующиеся на теории диэлектриков Мотта. При этом фазовый переход полупроводник-металл приводит к появлению избыточной концентрации электронов в легированной области и возникновению электрического поля, противодействующего их диффузии в нелегированную область. В некотором диапазоне температур и концентраций примеси возникает автоколебательный процесс, поддерживающий некоторое эффективное значение электродвижущей силы (ЭДС) [10]. Следует, однако, отметить, что физика данного явления существенно сложнее и включает привлечение термодинамики необратимых процессов. Эти вопросы являются предметом дальнейших исследований в данной области.

Образцы для исследования газочувствительности к этанолу представляли собой сандвич-структуры $\mathrm{ZnO} / \mathrm{ZnO}-\mathrm{Fe}$, оба слоя которых были сформированы методом погружения подложки в золь $[11,12]$. Нижний, нелегированный слой $\mathrm{ZnO}$ формировался в результате трех погружений для всех образцов, верхний слой $\mathrm{ZnO}-\mathrm{Fe}$ - в результате двух $(\mathrm{ZnO} / \mathrm{ZnO}-\mathrm{Fe}(2))$ и трех погружений $(\mathrm{ZnO} / \mathrm{ZnO}-\mathrm{Fe}(3))$. При $300^{\circ} \mathrm{C}$ в воздушной атмосфере ЭДС, возникающая в $\mathrm{ZnO} / \mathrm{ZnO}-\mathrm{Fe}(2)$, составляла $1 \mathrm{mV}$, а в $\mathrm{ZnO} / \mathrm{ZnO}-\mathrm{Fe}(3)-7 \mathrm{mV}$. Смена полярности знака возникающей ЭДС может быть обусловлена совокупностью различных факторов, решающий вклад которых зависит, по всей видимости, от условий проведения эксперимента.

1. Возникновение потенциального барьера под точечным контактом и возможность появления инверсного слоя. В этом случае система приобретает вид $n-n^{+}-p$ и в некотором диапазоне температур полярность снимаемой ЭДС будет меняться. Установлено, что с ростом

Письма в ЖТФ, 2017, том 43, вып. 18 


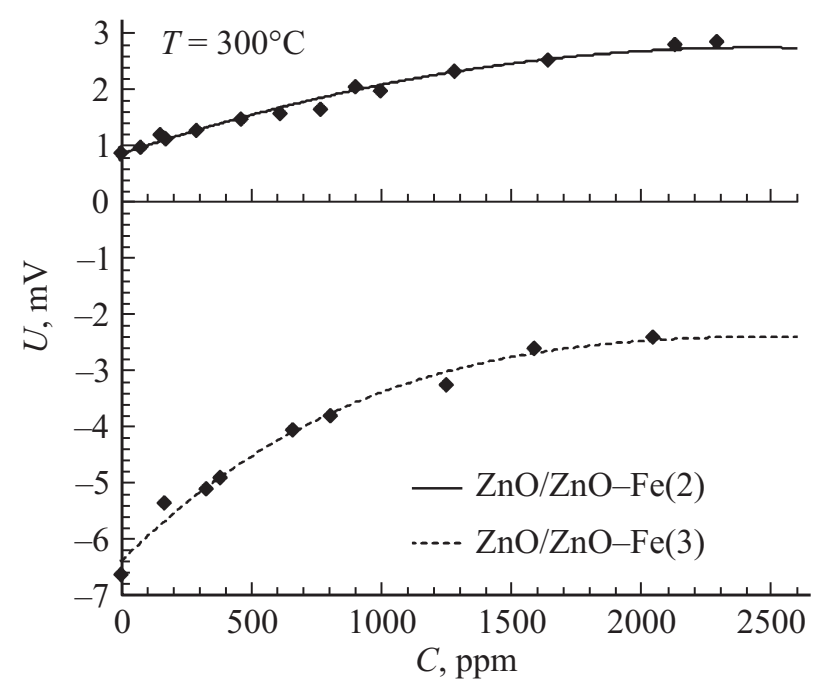

Рис. 1. Зависимость электродвижущей силы, возникающей в образцах, верхний слой которых сформирован двумя и тремя погружениями в золь, от концентрации паров этанола при $T=300^{\circ} \mathrm{C}$.

температуры за счет ионизации донорной примеси инверсный слой будет уменьшаться и при некотором критическом значении исчезнет. При дальнейшем увеличении температуры зависимость $U(T)$ для образцов $\mathrm{ZnO} / \mathrm{ZnO}-\mathrm{Fe}(3)$ и $\mathrm{ZnO} / \mathrm{ZnO}-\mathrm{Fe}(2)$ будет практически одинаковой.

2. Возникновение пьезо- и пироэлектрических эффектов в пленках оксида цинка. В этом случае возможна компенсация ЭДС, возникающей в результате термовольтаического эффекта, а также смена полярности ее знака.

3. Возникновение новых фаз на поверхности пленок (например, различных оксидов меди и железа), которые могут привести к появлению обедненных, обогащенных или инверсных слоев на границах раздела.

На рис. 1 показана температурная зависимость ЭДС, возникающей в образцах, от концентрации паров этанола в атмосфере. Механизм взаимодействия молекул этанола с поверхностью полупроводниковых оксидов можно описать с помощью схемы, показанной на рис. 2 [13].

Письма в ЖТФ, 2017, том 43, вып. 18 


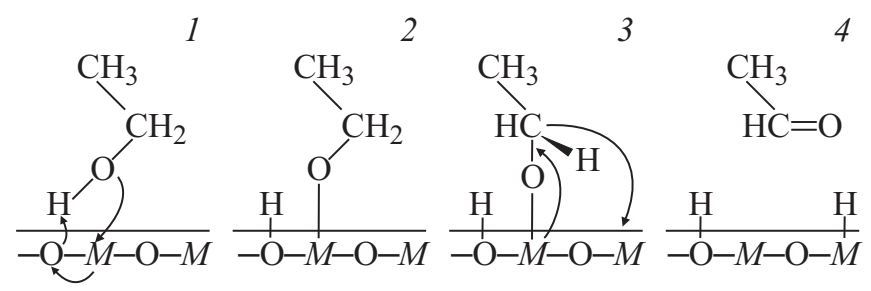

Рис. 2. Механизм взаимодействия молекул этанола с поверхностью полупроводниковых оксидов.

На этапах 1 и 2 происходит адсорбция молекул $\mathrm{CH}_{3} \mathrm{CH}_{2} \mathrm{OH}$ и образование поверхностных этоксидов. Следует отметить, что их количество коррелирует с числом катионов металлов на поверхности, которые обладают координационной ненасыщенностью. На этапах 3 и 4 происходит дегидрирование этоксидов с образованием молекул этилового альдегида (этаналь) и передача электрона в зону проводимости полупроводника. Таким образом, для $n$-полупроводника будет наблюдаться обогащение, а для $p$-полупроводника - обеднение.

На основании приведенного механизма хемосорбции возможно объяснение представленных на рис. 1 зависимостей. Для образцов $\mathrm{ZnO} / \mathrm{ZnO}-\mathrm{Fe}(2)$ возникающая ЭДС положительна и растет с увеличением концентрации паров этанола $C$. Вероятно, это связано с обогащением верхнего слоя образца $n^{+}$-типа электронами и увеличением эффективного значения ЭДС. Для образцов $\mathrm{ZnO} / \mathrm{ZnO}-\mathrm{Fe}(3)$ характерно возникновение инверсного слоя под точечным контактом и образование материала $p$-типа. При адсорбции этанола в этой области происходят процессы обеднения дырками и соответственно рассасывание $p$-области $n-n^{+}-p$-структуры. При этом модуль значения ЭДС с повышением концентрации этанола будет уменьшаться.

На основании результатов, показанных на рис. 1, была рассчитана зависимость газочувствительности образцов от концентрации паров этанола по следующей формуле:

$$
S=\left|\frac{U-U_{0}}{U_{0}}\right| \cdot 100 \%,
$$

где $U_{0}$ и $U-$ значения возникающей ЭДС на воздухе и в парах этанола соответственно. Результаты расчета представлены на рис. $3, a$. 

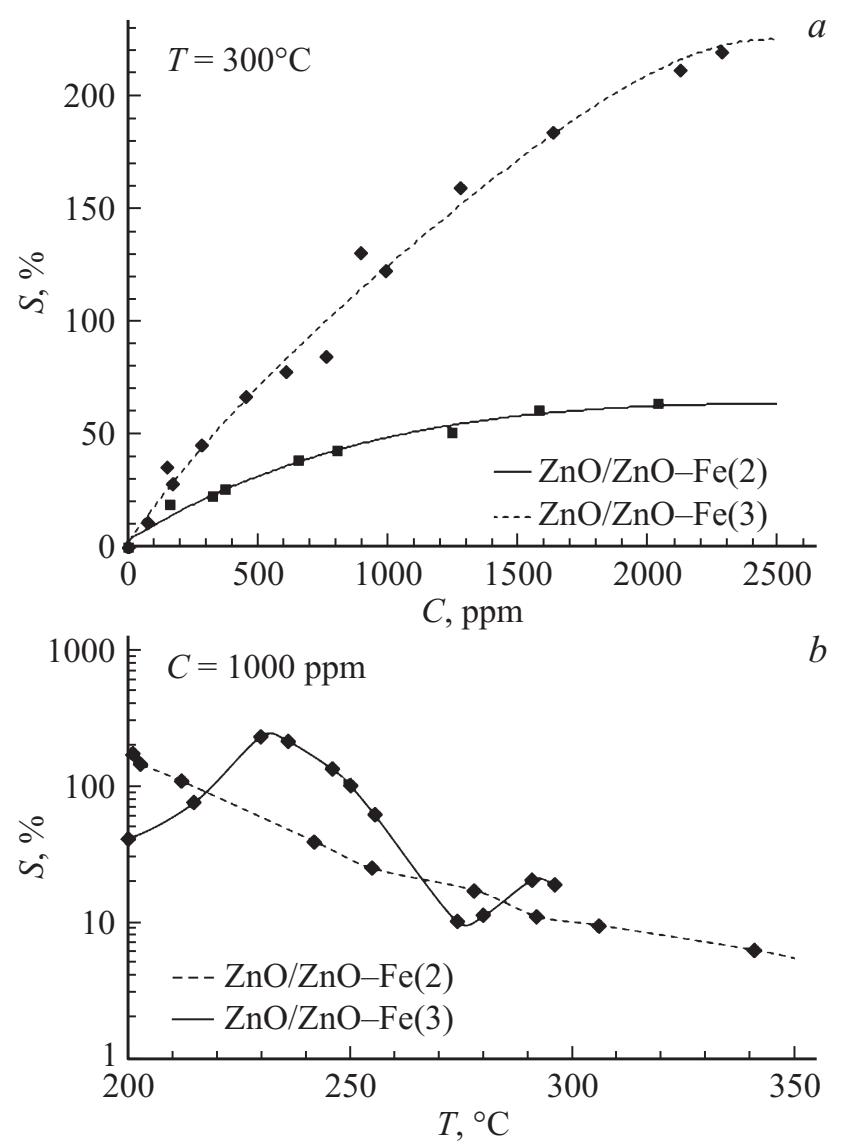

Рис. 3. Зависимость газочувствительности образцов от концентрации паров этанола $(a)$ и температуры $(b)$.

Письма в ЖТФ, 2017, том 43, вып. 18 
Видно, что во всем диапазоне исследованных концентраций газочувствительность образцов $\mathrm{ZnO} / \mathrm{ZnO}-\mathrm{Fe}(3)$ в 3-4 раза больше, чем у $\mathrm{ZnO} / \mathrm{ZnO}-\mathrm{Fe}(2)$. Это, вероятно, связано с бо́льшими значениями модуляции концентрации дырок в инверсном слое при процессах хемосорбции у первой серии образцов.

На рис. 3, $b$ представлена температурная зависимость газочувствительности исследуемых образцов. Максимальное значение $S(\sim 230 \%)$ показывают образцы $\mathrm{ZnO} / \mathrm{ZnO}-\mathrm{Fe}(3)$ при температуре $240^{\circ} \mathrm{C}$. Вид представленных зависимостей определяется, по всей видимости, взаимным переходом различных форм хемосорбированного кислорода при изменении температуры.

Таким образом, установлены особенности возникновения аналитического отклика нового типа газовых сенсоров на основе термовольтаического эффекта в оксиде цинка, неоднородно легированном примесями переменной валентности. Установленный эффект может быть положен в основу создания сенсоров нового типа.

Работа выполнялась при финансовой поддержке Министерства образования и науки РФ (проект № 16.897.2017/4.6).

\section{Список литературы}

[1] Yamazoe N. // Sens. Actuat. B. 1991. V. 5. P. 7-19.

[2] Gopel W. // Sens. Actuat. 1989. V. 16. P. 167-193.

[3] Аверин И.А., Игошина С.Е., Мочников В.А. и др. // ЖТФ. 2015. Т. 85. В. 6. C. $143-147$.

[4] Takahashi T., Yamada O. // J. Phys. Chem. Solids. 1976. V. 17. P. 161-165.

[5] Каминский В.В., Соловьев С.М. // ФТТ. 2001. Т. 43. Вып. 3. С. 423-426.

[6] Абрамович А.И., Королева Л.И., Долэкенкова Ю.В., Шимчак Р. // ФТТ. 2014. T. 56. В. 3. С. 484-487.

[7] Саидов А.С., Лейдерман А.Ю., Каршиев А.Б. // Письма в ЖТФ. 2016. Т. 42. B. 14. C. 21-27.

[8] Лейдерман А.Ю., Саидов А.С., Карииев А.Б. // Гелиотехника. 2016. В. 2. C. $48-51$.

[9] Пронин И.А., Аверин И.А., Божсинова А.С. и др. // Письма в ЖТФ. 2015. T. 41. В. 19. С. 23-29.

[10] Каминский В.В. // Письма в ЖТФ. 2013. Т. 39. В. 15. С. 12-17.

[11] Кононова И.Е., Мошников В.А., Криштаб М.Б., Пронин И.А. // Физика и химия стекла. 2014. Т. 40. В. 2. С. 244-261.

[12] Pronin I.A., Goryacheva M.V. // Surf. Coat. Tech. 2013. V. 235. P. 835-840.

[13] Idriss H., Seebauer E.G. // J. Mol. Catal. A. 2000. V. 152. P. 201-212. 